\title{
A distinctive fraction of alkaline phosphatase in health and disease
}

\author{
M. A. NEWTON \\ From the Metabolic Unit, University College Hospital, London
}

SYNOPSIS An electrophoretic fraction of plasma alkaline phosphatase, which migrates more slowly than the main fraction, was present in one fifth of normal subjects, and in some patients with parenchymal liver disease. It was absent in patients with bone disease, uncomplicated biliary obstruction, and hepatic metastases.

The electrophoretic and inhibition properties of this slow band were similar to those of intestinal phosphatase, and its significance is discussed.

In a patient with hypophosphatasia this fraction was apparently not decreased.

Since the demonstration of alkaline phosphatase in extracts of different tissues and of its activity on a multiplicity of substrates (Kay, 1932), evidence has accumulated for the heterogeneous nature of the enzymes contained in this non-specific group. This has extended from early attempts to find differences in behaviour towards inhibitors (Bodansky, 1937; Cloetens, 1939) to the first reported work on chromatography (Fahey, McCoy, and Goulian, 1958) and starch-block electrophoresis (Keiding, 1959; Rosenberg, 1959).

With the advent of starch-gel electrophoresis (Smithies, 1955), the evidence for multiple forms of alkaline phosphatase has grown, and there are several reports of the use of this method for the investigation of raised levels in bone and hepatobiliary disease. The main phosphatase activity migrates with $\beta$-globulin (Estborn, 1959), and the features of this fraction are useful in the distinction between liver and bone disease (Moss, Campbell, Anagnostou-Kakaras, and King, 1961; Hodson, Latner, and Raine, 1962).

Several authorities have commented on the appearance of additional bands of alkaline phosphatase in disease. Boyer (1961) found 16 such fractions but concluded that they were of no assistance in differential diagnosis. Chiandussi, Greene, and Sherlock (1962) noted an extra band in the haptoglobin region in four out of 11 cases of portal cirrhosis, though they were uncertain of its relation to the disease. Hodson et al. (1962) reported a similar band in some normal sera, though not in

Received for publication 8 March 1966

Present address: St. Mary's Hospital, London, W.2. any of their cases with liver or bone disease. They noted that its migration position corresponded to that of alkaline phosphatase from intestinal extract. The presence of this slower band in addition to the main band has been confirmed in surveys of normal subjects, plasma showing this appearance being called type 2 (Arfors, Beckman, and Lundin, 1963a and b; Beckman, 1964). These surveys and more recent ones (Bamford, Harris, Luffman, Robson, and Cleghorn, 1965; Shreffler, 1965) have shown that there are genetic factors controlling the manifestation of the slow band of alkaline phosphatase, its appearance being associated with blood groups 0 and $\mathrm{B}$, and the secretion of $\mathrm{ABH}$ substances.

It was decided to investigate the incidence of this subsidiary band in plasmas with raised alkaline phosphatase levels and to evaluate its diagnostic significance. Inhibitor studies were undertaken in order to investigate its nature, particularly as similar studies in normals have indicated an intestinal origin (Fishman and Kreisher, 1963).

Throughout this report, the term 'phosphatase' refers to alkaline phosphatase (Delory and King, 1945).

\section{MATERIAL}

Plasma was taken from 50 volunteer normal adults, from 121 patients with a raised alkaline phosphatase level, and from six patients with hypophosphatasia. Some patients with reversible liver damage were followed up and electrophoresis was repeated after the phosphatase had fallen to normal levels.

Extracts of alkaline phosphatase were made from fresh post-mortem normal small intestine, and from intestinal juice obtained by duodenal intubation. These 
preparations were extracted by n-butanol (Morton, 1950), and concentrated by Visking membrane dialysis against a $30 \%$ solution of Carbowax $20 \mathrm{M}$. Similar extracts were made from fresh post-mortem samples of normal liver, pancreas, and bone from a child.

\section{METHODS}

Horizontal starch-gel electrophoresis (Smithies, 1955) was carried out for five to six hours at 4.7 volts $/ \mathrm{cm}$. gel, using $0.076 \mathrm{M}$ Tris-citrate buffer and a discontinuous buffer system (Poulik, 1957). Alkaline phosphatase activity was located by incubation at $37^{\circ} \mathrm{C}$. with sodium $\alpha-1$-naphthyl phosphate $(0.005 \mathrm{M})$, in bicarbonate buffer $p \mathrm{H} 10.00$ (Delory and King, 1945), in the presence of magnesium chloride $(0 \cdot 005 \mathrm{M})$. The liberation of $a-1$ naphthol was detected by its fluorescence in ultra-violet light, and it was stained by pouring on to the gel a fresh aqueous solution of diazo-o-dianisidine. After about a minute, the preparation was rinsed and fixed by a methanol-acetic-acid-water solution.

Quantitative inhibition of alkaline phosphatase was studied by a variation of the method of King (1951) for the determination of the plasma level. The substances used were 1-phenylalanine $(0.01 \mathrm{M})$ and sodium taurocholate $(0.025 \mathrm{M})$. The inhibitor was dissolved in the routine bicarbonate buffer, and the concentration given is that of the final incubation mixture, obtained after the addition of an equal volume of the substrate solution, containing disodium phenyl phosphate $(0 \cdot 01 \mathrm{M})$. This mixture and a similar mixture, which did not contain inhibitor, were simultaneously warmed to $37^{\circ} \mathrm{C}$., together with a control solution for each. To these control solutions was added $1.8 \mathrm{ml}$. Folin and Ciocolteau reagent. Plasma or extract, $0.2 \mathrm{ml}$, was added to each of the four tubes, and incubation allowed to proceed for exactly 15 minutes. At its termination, $1.8 \mathrm{ml}$. Folin and Ciocolteau reagent was added to the test mixtures. The remaining procedure was according to the routine colorimetric method of King. Some of these determinations were done in duplicate, and there was close agreement in the degree of inhibition of a given phosphatase sample.

For demonstrating the differential inhibition of alkaline phosphatase on starch gel after electrophoresis, 1phenylalanine, $0.01 \mathrm{M}$, was made up in the incubation mixture, described above for use with gels. The gel was sliced horizontally, and the two halves were simultaneously incubated at $37^{\circ} \mathrm{C}$., one with the plain substrate buffer solution and the other with the solution containing inhibitor. At the earliest appearance of fluorescence in ultra-violet light, the incubations were stopped, and the gels stained and fixed.

\section{RESULTS}

All the 50 normal subjects had a main phosphatase band in the $\beta$-globulin region, but 10 also had a slowmoving band in the haptoglobin region. The slow band was also present in the plasmas of eight out of 18 patients with parenchymal liver disease (Table I). This group consisted of cases of infective hepatitis
TABLE I

DISTRIBUTION OF SLOW BAND

\begin{tabular}{|c|c|c|c|}
\hline Subjects & Total & $\begin{array}{l}\text { Slow } \\
\text { Band }\end{array}$ & $\begin{array}{l}\text { Significance Compared with } \\
\text { Distribution in Parenchyma } \\
\text { Liver Disease }\end{array}$ \\
\hline $\begin{array}{l}\text { Normal } \\
\text { Bone disease } \\
\text { Parenchymal }\end{array}$ & $\begin{array}{l}50 \\
56\end{array}$ & $\begin{array}{l}10 \\
\text { None }\end{array}$ & $\begin{array}{l}\text { Not significant } \\
P<0.001\end{array}$ \\
\hline $\begin{array}{l}\text { liver disease } \\
\text { Biliary obstruction }\end{array}$ & 18 & 8 & - \\
\hline and hepatic metastases & s 33 & 1 & $P<0.001$ \\
\hline
\end{tabular}

(eight), hepatic cirrhosis (seven), and congestive cardiac failure (three). The slow band was absent in 56 cases of bone disease with raised alkaline phosphatase levels, and in the group with biliary obstruction and liver metastases, there was only one patient who possessed the slow band (case 75). He had longstanding obstruction of the common bile duct by gallstones, with evidence of liver cell damage.

The alkaline phosphatase level of case 75 fell from 19 to 9 K.A. units $/ 100 \mathrm{ml}$. following cholecystectomy and removal of gallstones from the common bile duct. When this post-operative plasma was electrophoresed, the slow band had disappeared. Loss of the slow band was also seen in case 64 (infective hepatitis) following recovery, and in case 113 (elderly diabetic) following diabetic control and return of the phosphatase to a normal level (the nature of the liver damage was not established).

In two patients the slow band was the principal zone of alkaline phosphatase. The first was a patient with hypophosphatasia (M.P., Fig. 1). She was an adult with pathological fractures, whose case and family data are reported elsewhere (Bethune and Dent, 1960; Goyer, 1963). Neither her sister, an asymptomatic homozygote, nor her parents, who were heterozygous for hypophosphatasia, had the slow band. In four other cases of this condition, the

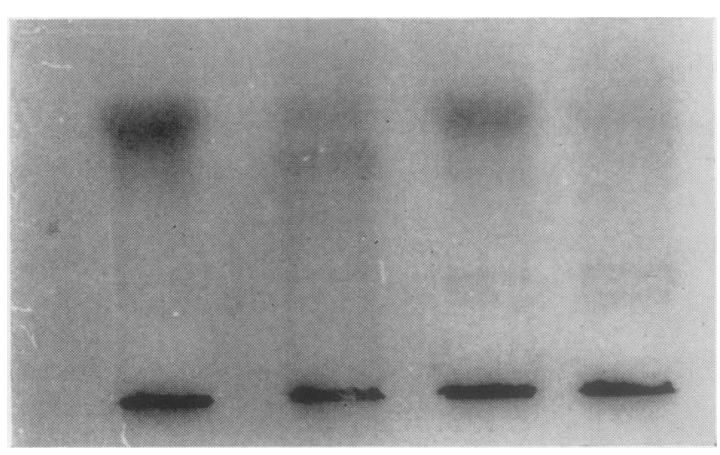

FIG. 1. From left to right: normal (7 K.A. units $100 \mathrm{ml}$.), M.P. (2 K.A. units $/ 100 \mathrm{ml}$ ), father of M.P. (6 K.A. units/100 ml.), sister of M.P. (1 K.A. unit/100 ml.). 


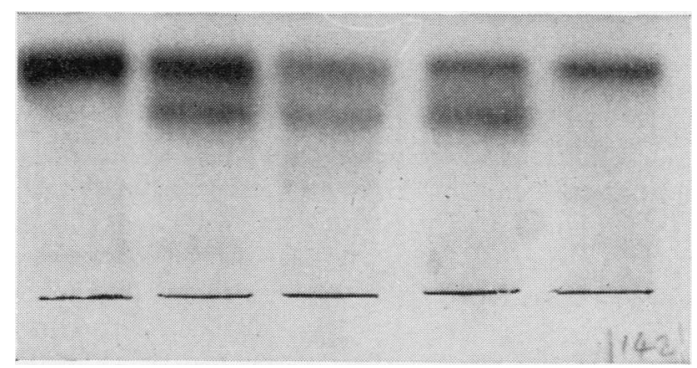

FIG. 2. From left to right: case 8 plasma (Paget's disease), case 8 plasma + intestine extract, case 106 plasma (cirrhosis), case 83 plasma (biliary obstruction) + intestine extract, case 83 plasma.

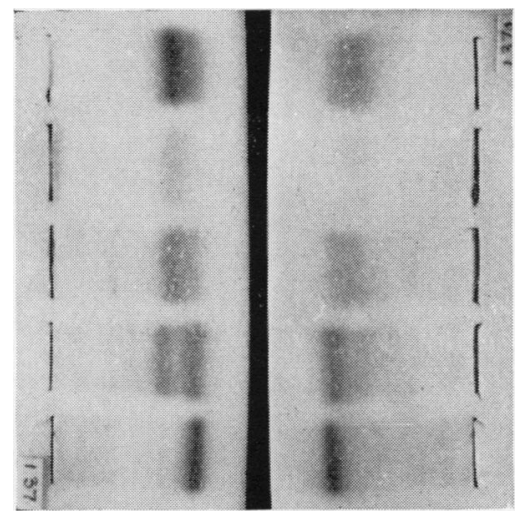

FIG. 3. The gel slice on the right was incubated in the presence of 1-phenylalanine. Samples, from above: intestine extract, intestinal juice extract; case 118 plasma (cirrhosis), case 106 plasma (cirrhosis), case 83 plasma (biliary obstruction).

slow band was not detected. The other patient with a strong slow band (case 118, Fig. 3) had advanced portal cirrhosis (proved histologically). The rest of the alkaline phosphatase in this case appeared as a faster slurred zone without any definite band in the $\beta$-globulin region. On follow-up, the phosphatase level had risen from 18 to 29 K.A. units $/ 100 \mathrm{ml}$., the increase apparently being wholly in the slow band.

The main alkaline phosphatase activity in extracts of intestine and duodenal juice corresponded with that of the plasma slow band (Fig. 3). When intestinal extract was mixed with plasmas having alkaline phosphatase only in the $\beta$-globulin region, the resulting electrophoretic pattern was identical to that of a type 2 plasma (Fig. 2).

The relative inhibition by 1-phenylalanine of intestinal and intestinal juice phosphatase and rela- tive sparing by taurocholate was demonstrated quantitatively (Figs. 4 and 5). The 'liver' samples consisted of plasmas with raised phosphatase concentrations due to hepatobiliary disease and a liver extract; the 'bone' samples were plasmas of patients with bone disease and a bone extract. The calculations for the $95 \%$ prediction intervals in these graphs were based on the data of all the samples other than the preparations of intestine and intestinal juice and cases 106 and 118 , as these were the four samples in which a slow band was present. With both inhibitors, the results of these four samples fell outside the $95 \%$ prediction intervals. Their failure to conform with the behaviour of the other phosphatase samples was
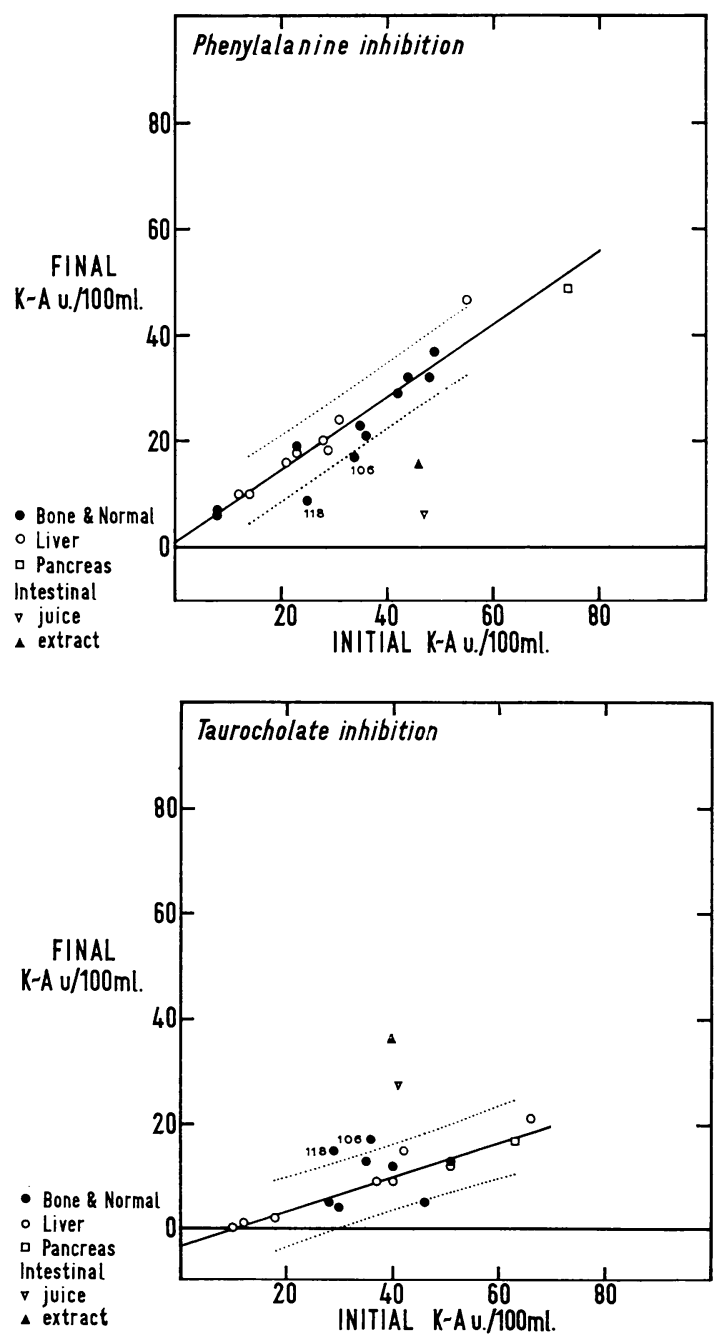

FIGS. 4 and 5. The area within the discontinuous lines is the $95 \%$ prediction interval. 
therefore significant $(P<0.05)$. The relative inhibition by 1-phenylalanine of the slow band and of intestinal phosphatase was demonstrated visually, when electrophoretic starch-gel strips were incubated in its presence (Fig. 3). The faster zones were relatively spared.

\section{DISCUSSION}

The finding of the slow band in one fifth of the normal adults agrees well with the figure of $21.2 \%$ in the survey of 468 subjects by Beckman (1964). Only definite slow bands were recorded as being present. Intensity of the band is variable, and arbitrary grading has been suggested (Bamford et al., 1965). If, in the series of Shreffler (1965), the groups with equivocal or weak slow bands are excluded, the incidence of this band is $17.5 \%$. (When they are included, the incidence becomes $55 \%$.)

The association of the slow band in normals with blood groups $\mathrm{O}$ and $\mathrm{B}$ and the $\mathrm{ABH}$ secretor status suggests a genetic determination (Arfors et al., 1963a and b; Beckman, 1964). The pattern of inheritance is not a simple one (Beckman, 1964), and would have to depend on more than one gene (Shreffler, 1965). Beckman showed that there is a much higher incidence in children under the age of 3 years $(42.6 \%)$, and Shreffler demonstrated a fluctuation in intensity of the band in the same individual at different times. It therefore seems reasonable to suppose that there are also non-genetic influences governing the appearance of the slow band. This is further suggested by the fact that in cases of disease with raised phosphatase levels, there was a specific distribution instead of being random throughout the groups.

The normal group was the only one in which the incidence of the slow band did not differ significantly from that in parenchymal liver disease, though in a larger survey a difference might well emerge. From analysis of the small groups studied, the important results are the virtual absence of this band in patients with bone disease and with biliary obstruction of all kinds, including that due to hepatic metastases. The presence, or otherwise, of the slow band is thus helpful in the diagnosis of the cause of a raised phosphatase level, especially when combined with observation of the electrophoretic appearance of the other phosphatase fractions (Newton, 1966).

The electrophoretic similarity of the slow band and intestinal phosphatase was well demonstrated in the experiment of mixing intestinal phosphatase with plasma (Fig. 2). The two preparations containing phosphatase of known intestinal origin showed a significantly increased inhibition by 1-phenylalanine and relative sparing by taurocholate, con- firming previous findings (Bodansky, 1937; Fishman, Greene, and Inglis, 1963). The significant deviation towards this trend of the two type 2 plasmas provided further evidence for the presence of intestinal phosphatase, and its identity with the slow band was confirmed by the visual inhibition studies following electrophoresis. The degree of inhibition in the plasmas of cases 118 and 106 deviated less far outside the prediction intervals than that in the two preparations of intestinal phosphatase. This can be explained by the smaller proportion of intestinal phosphatase contained in the plasmas.

The normal intensity of the slow band in a case of hypophosphatasia suggests that the production of this enzyme by intestine was relatively unimpaired, and is consistent with the theory that the abnormality is essentially confined to osteoid (Fraser, 1957). The view that the primary defect is in the production of phosphatase in all tissues (Korner, 1962) is not supported by the necropsy findings in a case of hypophosphatasia (McCance, Fairweather, Barrett, and Morrison, 1956) in which a marked decrease in the enzyme content of bone (1.5 K.A. units compared with a normal of $243 \mathrm{~K}$.A. units) contrasted with a barely significant decrease in intestine (210 K.A. units, normal 284 K.A. units). The phosphatase concentration in other tissues, including liver, was decreased to a similar extent to that in bone. This emphasizes the distinction between phosphatase from intestine, and that from liver or bone, which has already been pointed out in the inhibition studies, and is further demonstrated by their antigenic properties (Boyer, 1963).

The main phosphatase band in normal human plasma is probably derived from bone (Schlamowitz and Bodansky, 1959; Gutman, 1959) and is excreted into the bile after preliminary storage in the liver (Sherlock and Walshe, 1947; LeVeen, Talbot, Restuccia, and Barberio, 1950). It has been shown that the principal source of rat plasma phosphatase is intestine (Madsen and Tuba, 1952; Fishman, Greene, and Inglis, 1962), and it has been suggested, from the results of inhibition experiments, that human plasma also contains intestinal phosphatase (Fishman et al., 1963; Steenson and Evered. 1963). By combining electrophoresis and 1-phenylalanine inhibition, Fishman and Kreisher (1963) demonstrated that in normal plasma the slow band was intestinal phosphatase. It must be stressed that the intestine is neither the main source of plasma phosphatase nor can it be unequivocally detected in all subjects.

Because of the blood group association, it has been suggested that the slow band is a complex of phosphatase with secretor substance (Arfors et al., 1963b; Beckman, 1964), but, as the average phos- 
phatase level is higher in type 2 normals, it seems more likely to be an additional fraction, probably from an independent origin (Bamford et al., 1965).

Intestinal phosphatase presumably reaches the portal vein directly from the mucosal cells. The genetic and acquired factors which suppress its appearance in the systemic blood may act either by blocking its absorption into the portal blood, or by increasing bile excretion of intestinal phosphatase, so that none escapes into the systemic circulation. Such mechanisms must predominate in the presence of blood group $\mathrm{A}$, in non-secretors and in patients with raised phosphatase levels due to bone disease or hepatobiliary obstruction. When the slow band is seen in parenchymal liver disease, this may sometimes result from unsuppressed genetic factors which favour its appearance, but in three cases, the slow band was not evident after recovery and phosphatase fell to normal levels, suggesting that some acquired factor had been present during the disease, which had encouraged the appearance of intestinal phosphatase in the peripheral blood. A possible explanation may be that liver cell dysfunction permitted shunting of unexcreted intestinal phosphatase from the portal blood, and this may have been further encouraged by a degree of portal hypertension. It is interesting that a patient with cirrhosis who also had portal hypertension was unique in possessing most of his phosphatase in the slow band (case 118, Fig. 3). Further studies of such cases and of patients with surgical portal-systemic shunts would be of interest.

This work formed part of that reported in a thesis for the degree of M.D. Cantab., and was carried out with the help of a grant from the Medical Research Council. I am most grateful to Professor C. E. Dent for his support and to Dr. M. Pyke for advice in the statistical treatment of data.

\section{REFERENCES}

Arfors, K. E., Beckman, L., and Lundin, L. G. (1963a). Acta genet. (Basel), 13, 89

- (1963b). Ibid., 13, 366

Beckman, L. (1964). Ibid., 14, 286.

Bamford, K. F., Harris, H., Luffman, J. E., Robson, E. B., and Cleghorn, T. E. (1965). Lancet, 1, 530.

Bethune, J. E., and Dent, C. E. (1960) Amer. J. Med., 28, 615.

Bodansky, O. (1937). J. biol. Chem., 118, 341.

Boyer, S. H. (1961). Science, 134, 1002.

- (1963). Ann. N.Y. Acad. Sci., 103, 938.

Chiandussi, L., Greene, S. F., and Sherlock, S. (1962). Clin. Sci. 22, 425.

Cloetens, R. (1939). Enzymologia, 6, 46

Delory, G. E., and King, E. J. (1945). Biochem. J., 39, 245.

Estborn, B. (1959). Nature (Lond.), 184, 1636.

Fahey, J. L., McCoy, P. F., and Goulian, M. (1958). J. clin. Invest. 37, 272.

Fishman, W. H., Green, S., and Inglis, N. I. (1962). Biochim. biophys. Acta (Amst.), 62, 363.

- — (1963). Nature (Lond.), 198, 685.

, and Kriesher, J. H. (1963). Ann. N.Y. Acad. Sci., 103, 951

Fraser, D. (1957). Amer. J. Med., 22, 730

Goyer, R. A. (1963). Arch. Dis. Childh., 38, 205.

Gutman, A. B. (1959). Amer. J. Med,. 27, 875.

Hodson, A. W., Latner, A. L., and Raine, L. (1962). Clin. chim. Acta, $7,255$.

Kay, H. D. (1932). Physiol. Rev., 12, 384.

Keiding, N. R. (1959). Scand. J. clin. Lab. Invest., 11, 106.

King, E. J. (1951). Micro-analysis in Medical Biochemistry. Churchill, London.

Korner, N. H. (1962). J. clin. Path., 15, 200.

LeVeen, H. H., Talbot, L. J., Restuccia, M., and Barberio, J. R. (1950). J, Lab. clin. Med., 36, 192.

McCance, R. A., Fairweather, D. V. I., Barrett, A. M., and Morrison, A. B. (1956). Quart. J. Med., 25, 523.

Madsen, N. B., and Tuba, J. (1952). J. biol. Chem., 195, 741.

Morton, R. K. (1950). Nature (Lond.), 166, 1092.

Moss, D. W., Campbell, D. M., Anagnostou-Kakaras, E., and King, E. J. (1961). Pure appl. Chem., 3, 397.

Newton, M. A. (1966). Quart. J. Med. in press.

Poulik, M. D. (1957). Nature (Lond.), 180, 1477.

Rosenberg, I. N. (1959). J. clin. Invest., 38, 630

Schlamowitz, M., and Bodansky, O. (1959). J. biol. Chem., 234, 1433.

Sherlock, S., and Walshe, V. (1947). J. Path. Bact., 59, 615.

Shreffler, D. C. (1965). Amer. J. hum. Genet., 17, 71.

Smithies, O. (1955). Biochem. J., 61, 629.

Steenson, T. I., and Evered, D. F. (1963. Lancet, 2, 792. 